\title{
PWM Signal Generation for Dual inverter Fed Open-end Winding Induction Motor Drive Using Only the Instantaneous Reference Phase Amplitudes \\ M.R. Baiju K.K.Mohapatra K.Gopakumar \\ Centre for Electronics Design and Technology \\ Indian Institute of Science, INDIA. 560012
}

\begin{abstract}
A space vector modulation scheme for the dualinverter-fed open end winding induction motor drive, using only the instantaneous sampled reference voltages is presented in this paper. The proposed space vector PWM technique does not require the sector information and look-up tables to select the appropriate switching vectors for the two inverters. The inverter leg switching times are directly obtained from the instantaneous sampled reference voltage amplitudes and the inverter switching vectors are automatically generated. The proposed scheme ensures equal switching of the two inverters. The algorithm does not involve computations like square root and mapping of sectors. The proposed method is implemented on a 1-hp open-end winding induction motor drive and the results are presented.
\end{abstract}

Key words - open-end winding induction motor, space vector PWM

\section{INTRODUCTION}

Open-end winding induction motor drive configurations in which the three phase induction motor is fed by dual inverters(one inverter from one end of the winding set and the other inverter from the other end ) result in multi-level inverter structures suitable for high power applications [1]-[5]. A three-level inverter structure is obtained when the open-end winding induction motor is fed by 2-level inverters with half the DC-link voltages compared to that of the conventional neutral point clamped 3-level inverter [5].The implementation of the Space Vector Pulse Width Modulation ( SVPWM) for the dual inverter scheme involves the following steps.(a) identifying the sector in which the instantaneous reference space vector lies using level comparators along $\mathrm{jA}, \mathrm{jB}, \mathrm{jC}$ axes (b) mapping this sector to an appropriate sector in the inner hexagon through coordinate transformations (c) determination of the inverter vector switching times $\left(T_{0}, T_{1}\right.$ and $\left.T_{2}\right)$ selecting appropriate individual vectors using switching sequence tables [2][4]. At every switching period, the reference voltage space phasor is realized by switching between the nearest three inverter voltage space phasors which form the sector in which the reference vector resides. Each of the combined inverter voltage space phasor is realised by switching an appropriate combination of the individual inverter voltage space vectors .

The SVPWM method presented in this paper does not require sector identification and sector mapping. The inverter leg switching times are directly obtained from the instantaneous sampled reference phase voltages and the dual inverter switching vectors are automatically generated. The switching vectors for the individual inverters are derived using a simple digital logic. The proposed method uses an algorithm which does not involve any complex computations and hence the implementation time is reduced. The algorithm which includes an over-modulation strategy for the non-linear modulation range, is implemented on the TMS320F240 DSP platform for a Ihp open-end winding induction motor drive.

\section{DUAL INVERTER FED OPEN END WINDING INDUCTION MOTOR DRIVE}

A. Dual-inverter fed open-end winding induction motor The schematic of the dual inverter fed induction motor drive is shown in Fig.1. The open-end winding induction motor is fed from both the ends by two 2-level inverters ('Inverter-1' and 'Inverter-2'). The inverters are operated with isolated power supplies of half the DC-link voltage compared to that of the conventional 3-level inverter. The phase voltages of the induction motor $\left(\mathrm{v}_{\mathrm{A} 1 \mathrm{~A} 2}, \mathrm{v}_{\mathrm{B} 1 \mathrm{~B} 2}, \mathrm{v}_{\mathrm{ClC} 2}\right)$ can independently attain three levels $-\mathrm{V}_{\mathrm{dc}} / 2,0$ and $\mathrm{V}_{\mathrm{dc}} / 2$ (represented with '-' , ‘ 0 ' and ' + ' respectively ) depending on the individual pole voltages of 'Inverter-1' and 'Inverter-2'. The ' 0 ' level in any phase can be realised under two conditions. If the pole voltages of both the inverters at particular legs are at $\mathrm{V}_{\mathrm{dc}} / 2$ or if both pole voltages are at 0 , the respective phase attains ' 0 ' voltage level. This multiplicity available for the ' 0 ' level is an unique characteristic of the dual inverter scheme.

\section{B. Space vector representation of the dual inverter}

The voltage space vector representation of the dual inverter, where the three possible levels are represented as '+','-' and ' 0 ' is given in Fig 2. These space phasors are actually the combined effect of the individual voltage space vectors of the 2-level inverters. As the inverters are driving the motor from opposite ends, the resultant space vectors can be obtained by performing the vector subtraction of the space vectors generated by the individual inverters. Fig.3 shows the space vector representation of the dual-inverter and all the possible 64 combinations which would realise the combined space phasors [2]. The states of 'Inverter-I' are represented as 1,2,3 etc. and states of 'Inverter-2' are represented as 1', 2',3'etc. When we compare this space phasor representation with that of the conventional three-level inverter, it can be seen that more combinations are available at certain locations. The presence of more combinations in the dual 
inverter scheme can be attributed to the multiplicity in ' 0 ' level.

\section{THE PROPOSED SPACE VECTOR BASED PWM FOR THE DUAL-INVERTER}

The SVPWM proposed in this paper views the dual-inverter fed open-end winding induction motor as a three-level inverter structure with the space vector representation as in Fig.2. The proposed algorithm has three parts for the different regions of operations of the dual inverter. Three regions can be identified in the space vector diagram ( Fig.2 ) - the inner region containing the inner six sectors (sector 1 to sector 6 ), the outer region consisting of the outer sectors ( sector 7 to sector 24 ) and the overmodulation region which lies out side all the sectors. If $\mathrm{V}_{m}$ and $\mathrm{V}_{\min }$ are the instantaneous maximum and minimum values of the three instantaneous sampled reference phase amplitudes, it can be verified that the tip of the reference vector will be in the inner region if $\left(\mathrm{V}_{\max }-\mathrm{V}_{\min }\right)<\mathrm{V}_{\mathrm{dc}} / 2$. The tip of the reference vector will be in the outer region if $\left(V_{\max }-V_{\min }\right)>V_{d c} / 2$ and it will be in the over-modulation region if $\left(\mathrm{V}_{\max }-\mathrm{V}_{\min }\right)>\mathrm{V}_{\mathrm{dc}}$.

\section{A. The space phasor is in the inner region}

Let us consider a situation in which the peak phase voltage is $\mathrm{V}_{\mathrm{dc}} / 5$ so that $\mathrm{V}_{\max }-\mathrm{V}_{\min }<\mathrm{V}_{\mathrm{dc}} / 2$. The reference space phasor is inside the inner region and Fig. $4 \mathrm{a}$ shows this condition when the middle phase is negative.

It is seen from the figure that of the three phases, it is the maximum phase which crosses any of the triangular carriers first ( the upper one in this case) and hence causes the inverter to change state. The minimum phase crosses the triangular wave (lower triangular wave) as the second and hence effects the next change in inverter state. Finally the middle phase crosses as the third. So as the phase voltages cross the triangular waves one by one, the inverter changes state and respective space vectors are generated. The switching time duration for each vector within a switching time period, may be referred as $\mathrm{T}_{01}, \mathrm{~T}_{1}, \mathrm{~T}_{2}$ and $\mathrm{T}_{03}$. $\mathrm{T}_{01}$ and To3 are duration for the starting and ending vectors and $T_{1}$ and $T_{2}$ are duration for the two middle vectors.

Let us consider one switching period $\left(T_{S}\right)$ as seen Fig $4 \mathrm{~b}$. At the instant shown in the figure, it is the B-phase which is the maximum phase, A-phase is the middle phase and C-phase is the minimum phase. Let us refer the time at which reference waves cross the triangular waves for the

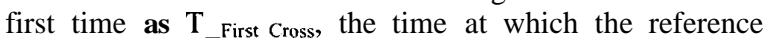
waves cross the triangular waves for the second time as $T$ second_Cross and time which reference waves cross the triangular waves for the third time as $\mathbf{T}$ Third Cross. For every sample time period , a similar picture will emerge, but the maximum, middle and minimum phases could be either A-phase, B-phase or C-phase . It may be noted that these timings have a direct relation with the respective phase voltages [2][7]. For the situation shown in Fig.4b, from the geometry of the figure it can be seen that $T_{-}$First Cross, T_Second-Cross and $\mathbf{T}$ Third Cross are calculated as in eqn.1. This case in which the reference vector is inside the inner region and the middle phase is negative is referred as CASE1.

CASEI: The reference vector is in the inner region and middle phase is negative

$T_{-}$First_Cross $=V_{\max } \times\left(\frac{T_{S}}{v_{d d} / 2}\right)=T_{\max }$

$T_{-}$Third_Cross $=\left(v_{d c} / 2+v_{\text {mid }}\right) \times\left(\frac{T_{s}}{v_{d c} / 2}\right)=T_{S}+T_{\text {mid }}$

$\mathrm{T}_{-}$second_Cross $\left.=\left(\mathrm{v}_{\mathrm{dc}} / 2+\mathrm{V}_{\min }\right) \times\left(\frac{\mathrm{T}_{\mathrm{S}}}{\mathrm{v}_{\mathrm{dc}} / 2}\right)=\mathrm{T}_{\mathrm{s}}+\mathrm{T}_{\min }\right)$

It can be verified that another situation when the space phasor is inside the inner region is when the middle phase is positive[6].

CASE 2: The reference vector is in the inner region and $V_{\text {mid }}$ is Positive

$\left.\begin{array}{ll}\mathrm{T}_{\text {First_Cross }}=\mathrm{T}_{\text {mid }} & \mathrm{T}_{\text {_m second-Cross }}=\mathrm{T}_{\max } ; \\ \mathrm{T}_{\text {_Third_Cross }}=\mathrm{T}_{\mathrm{s}}+\mathrm{T}_{\min } & \end{array}\right\}$

$B$. The reference vector is in the outer region

When the tip of the reference vector is in the outer region there are four different situations possible. These four different conditions ( CASE 3 to CASE 6) and the calculation of the $T_{-}$First_Cross $T_{-}$Second_Cross and $T_{-}$Third_Cross timings are given by the following equations.

CASE3: reference vector is in the outer region and $V_{\text {mid }}$ is positive an $d V_{\text {mid }}<\left(\mathrm{V}_{\mathrm{dc}} / 2+V_{\text {min })}\right.$

$$
\left.\begin{array}{l}
\mathrm{T}_{\text {_First_Cross }}=\mathrm{T}_{\text {mid }} \\
\mathrm{T}_{\text {_Third_Cross }}=\mathrm{T}_{\max }
\end{array}\right\}
$$

CASE 4: reference vector is in the outer region and $V_{\text {mid }}$ is positive and $V_{\text {mid }}>\left(\mathrm{V}_{\mathrm{dc}} / 2+V_{\text {min }}\right)$

$$
\left.\begin{array}{l}
\mathrm{T}_{\text {__ First_Cross }}=\mathrm{T}_{\mathrm{s}}+\mathrm{T}_{\min } \quad \mathrm{T}_{\text {__second_Cross }}=\mathrm{T}_{\text {mid }} \\
\mathrm{T}_{\text {_CTird_Cross }}=\mathrm{T}_{\max }
\end{array}\right\}
$$

CASE5: reference vector is in the outer region and $V_{\text {mid }}$ is negative and $V_{\max }>\left(\mathrm{N}_{\mathrm{dc}} / 2+V_{\text {mid }}\right)$

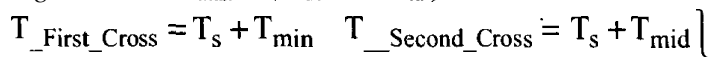

$\mathrm{T}_{\text {Third_Cross }}=\mathrm{T}_{\max }$

CASE 6 :reference vector is in the outer region and $V_{\text {mid }}$ is negative and $\left(\mathrm{V}_{\mathrm{dc}} / 2+V_{\text {mid }}\right)>V_{\text {max }}$

$\left.\begin{array}{ll}T_{\text {_First_Cross }}=T_{\mathrm{s}}+\mathrm{T}_{\min } & \mathrm{T}_{\text {__second-Cross }}=\mathrm{T}_{\max } \\ \mathrm{T}_{\text {_Third_Cross }}=\mathrm{T}_{\mathrm{s}}+\mathrm{T}_{\text {mid }} & \end{array}\right\}$

CASE1 to CASE6 are the six different situations possible when the inverter is in the linear modulation region [6]. Depending upon the instantaneous values of the reference voltages, eqn.1 to eqn. 6 define the timings at which the reference phase voltages crosses the triangular waves and effect changes in the inverter state. The control algorithm of the proposed PWM method uses these timings ( $T_{\text {First Cross }}$ $\mathrm{T}_{\text {Second Cross and }} \mathrm{T}_{\text {Third Cross }}$ ) to directly arrive at the 
switching vectors of the dual inverter and the switching times.

\section{Principle of the proposed SVPWM}

Let us consider one sampling time period $\left(\mathrm{T}_{\mathrm{S}}\right)$ of the condition where the reference space vector is in the inner region and the middle phase is negative as shown in Fig.5 ( CASE1, Fig.4a expanded ). The $T_{\text {_First_Cross }} \mathrm{T}_{\text {Second_Cross }}$ and $\mathrm{T}$ Third_Cross timings are determined from the instantaneous phase values as given by eqn.1. Within one switching period $\left(T_{S}\right), T_{-F i r s t \text { Cross }}$ and $\left(T_{S}-T_{\text {Third Cross }}\right)$ are the time period for the start and end vectors of a triangular sector. The remaining time is referred as the effective vector time $\mathrm{T}_{\text {effective. }} \boldsymbol{A n}$ offset value can be added to the $\mathrm{T}_{\text {First Cross }}$ time period such that $T_{\text {_First Cross }}+T_{\text {Offset }}=T_{z \text { ero }} / 2$.

$$
\begin{aligned}
& T_{\text {zero }}=T_{s}-\left(T_{\text {_Third_Cross }}-T_{\text {_First_Cross }}\right) \\
& T_{\text {_First_Cross }}+T_{\text {Otfset }}=T_{\text {zero }} / 2 \\
& T_{\text {Offset }}=T_{\text {zero }} / 2-T_{\text {First_Cross }}
\end{aligned}
$$

The addition of this offset voltage will to $T_{\text {_First Cross }}$ will now give $T_{\text {g_First_Cross }}$ which is the switching time duration for that phase of the dual inverter which determines $T_{\text {_First_Cross }}$. If the same offset time is added to $T_{\text {Second Cross }}$ and $\tilde{T}_{\text {_r Third_Cross }}$, switching times for the other two inverter phases $T_{g}$ Second_cross and $T_{g}$ Third_Cross are also obtained.

$T_{g}$ First-Cross $=T_{\text {__First_Cross }}+T_{\text {Offiset }}$

$T_{\mathrm{g}}$ Second-Cross $=T_{-}$Second_Cross $+T_{\text {Offset }}$

$\mathrm{T}_{\mathrm{g} \text {-Third-Cross }}=\mathrm{T}_{\text {Third Cross }}+\mathrm{T}_{\text {Offset }}$

As the same offset time is added to

The Tirst_Cros T second-Cross and T_Third_Cross times (Fig.5), the duration of the middle vectors $\left(T_{\text {effective }}\right)$ remains unchanged. Since the $T_{\text {g_First_Cross }}$ has been made equal to $T_{\text {zero }} / 2$ and the middle vector duration remains unchanged, the last vector duration is also $\mathrm{T}_{\text {zero }} / 2$ so that the middle vectors are now centered within the switching time period $\mathrm{T}_{\mathrm{S}}$. A similar procedure has been implemented for the two level inverter space vector based PWM [7].

It can be seen that in Fig. 4a the maximum phase , minimum phase and middle phase determine $\mathbf{T}$ _first Cross, $T_{\text {_second_Cross }}$ and $T_{\text {_third_cross }}$ respectively . But maximum middle and minimum phases alternate between $A, B, C$ phases. During the switching period shown in Fig.5 it is the B-phase (maximum phase) which determines T_First_cross , hence $\mathrm{T}$, First_cross $=\mathrm{T}_{\mathrm{gb}}$. Similarly the C-phase ( minimum phase) determines $\mathrm{T}_{\text {sscond_Cross }}$ and $\mathrm{B}$-phase (middle phase) determines $T_{\mathrm{g} \_ \text {Third_Cross }}$ so that

$\mathrm{T}_{\mathrm{g} \_ \text {Second-Cross }}=\mathrm{T}_{\mathrm{gc}}$ and $\mathrm{T}_{\mathrm{g}}$ Third-Cross $=\mathrm{T}_{\text {ga }}$ where $\mathrm{T}_{\mathrm{ga} .} \mathrm{T}_{\mathrm{gb} \text {. }}$ and $T_{g c}$ are the switching times for the $A, B, C$ phases of the dual inverter as shown in Fig.5.

The example we have taken is one condition, (referred as CASE 1)where the reference vector is inside the inner region and $V_{\text {mid }}$ is negative. This procedure can be used for the remaining five cases also (CASE 2 to CASE 6). It can be verified that appropriate inverter voltage vectors in different sectors are automatically generated as the A,B,C phases change roles as minimum, maximum and middle
phases.For each case the $T_{r} T_{g b}$ and $T_{g c}$ timings can be determined as done for the CASEl(eqn.8 to eqn.10) .Therefore the algorithm along with $\mathrm{T}_{\mathrm{ga}}, \mathrm{T}_{\mathrm{gb}}, \mathrm{T}_{\mathrm{gc}}$ values also generates the information of the sign of the reference voltage. It may be noted that this algorithm does not involve any complex computations .

\section{GENERATION OF THE COMBINED SWITCHING} VECTORS FOR THE DUAL INVERTER

Once we determine the switching times of the phases of dual inverter, the state of the dual inverter can be uniquely determined if we also know the levels each phase occupies, at every instant. At the instant depicted in Fig.5, B-phase is positive and hence switches between " + "and ' $O$ ' while A-phase and C-phase being negative switch between ' 0 ' and ' - '. The inverter phase switching levels uniquely define the state of the dual inverter and hence the vector to be switched are automatically obtained. In Fig5, within a switching cycle, the inverter assumes the states $' 0+0^{\prime}, 000$ ', $00-$ ', and ' $-0-^{\prime}$. These are the vectors forming sector 2 (Fig. 2) and at this particular instant the tip of the reference vector is in sector 2 . Hence without identifying the sector and without employing any look up table, we have arrived at the appropriate combined switching vectors of dual inverter to be switched to realise the reference voltage space phasor.

\section{DERIVING THE SWITCHING VECTORS FOR THE INDIVIDUAL INVERTERS}

The translation of the these combined switching vectors to respective combinations of the switching vectors of the individual inverters can be achieved by a simple digital logic as explained in this section. For optimum switching, the switching vectors of the individual inverters should be such that the transition from one state of the dual inverter to another state is achieved by switching only one inverter leg. Also, it should also be ensured that both the 2 level inverters are switching equally.

Let us look at the situation where the tip of the reference space phasor in sector 2 and the sequence is '0+0', '000', '00-', and '- 0 -' as seen in Fig.5. The ' 0 ' level in any phase could be realised in two ways, by switching the top switches or the bottom switches of the inverters in the respective legs. If we choose only one of these possibilities it would result in either top or bottom switches switching more frequently. In the method proposed in this paper, the multiplicity is resolved by applying the rule that if any phase of the dual inverter is alternating between ' + ' and ' 0 ' levels (ie when the respective reference voltage is positive ), the ' 0 ' level is achieved by switching the top switches of ' the respective legs of the individual inverters and if any phase is alternating between ' 0 ' and '-' levels( ie when the corresponding reference voltage is negative ), the ' 0 ' level is realised by switching the bottom switches of the respective legs of the two inverters. With this rule, both the ' 0 ' level conditions would be selected equally. 
Let us apply this rule to the situation in Fig.5, where the switching vectors of the dual inverter are ' $0+0$ ', 000 ', '00-' and ' -0 -'. During the switching period shown in this figure, the A-phase and C-phase reference voltages are negative and $\mathrm{B}$-phase reference voltage is positive. Hence in $\mathbf{A}$ and $\mathbf{C}$ phases of the dual inverter, the ' 0 ' level is attained by switching on the bottom switches of the individual inverters and in B-phase the ' 0 ' level is attained by switching the top switches of the C-legs. Then the individual inverter states corresponding to the dual inverter state of ' $0+0$ ', are '-+-'( 3 ) and '---'( 8 ' ).This combination is referred as 38' at location 4 in Fig.3. For the '000' state, the individual vectors are '-+-'(3) and '-+-' (3'), the combination being 33'. So' the combination for the sequence ' $0+0$ ', '000', '00-', '- 0 -' is $38^{\prime}, 33^{\prime}, 34^{\prime}$ ' and 37 '. We may observe that the transitions from one state of the dual inverter to another state is achieved by switching only one inverter leg. It is also to be noted that the 'Inverter-1' is clamped to state 3 while the 'Inverter-2' is switching amongst its appropriate adjacent states. . Similarly we can find out the combinations of the individual inverters in all the sectors. It can be verified that as reference vector moves the inner region (sector1 to sector 6) once, Inverter-1 is switches less frequently (switching only six times, ie once in every 60 degree ) while inverter- 2 switch very frequently ( three times in every switching time period $T_{\mathrm{S}}$ ). The total switchings in both the inverter could be made equal, if for alternate fundamental cycles of the reference wave, the nature of switching in the inverters are reversed. If for one cycle Inverter-2 is switching more, in the next fundamental cycle Inverter-2 should switch less . In the work presented in this paper this is achieved by reversing the rule used to resolve the ' 0 ' level multiplicity. For one cycle of the modulating signal, the ' 0 ' level when the reference wave is positive is attained by switching the top switches and the ' 0 ' level when the reference wave is negative, is realised by switching the bottom switches. In next cycle the ' 0 ' level when the reference wave is positive, is attained by switching the bottom switches and the ' 0 ' level when the reference wave is negative, is realised by switching the top switches. If we apply this rule to the situation taken as example above (when the reference vector is in sector 2) the dual inverter switching vectors corresponding to the sequence ' $0+0$ ', 000 ', '00-', ' 0 -' for one fundamental cycle is $38^{\prime}, 33^{\prime}, 34^{\prime}$ ' and $37^{\prime}$ ' ( in A and C legs the ' 0 ' level is attained by switching on the bottom switches of the individual inverters and in B-phase the ' 0 ' level is attained by switching the top switches ) For the same sequence ,the actual switching vectors of the dual inverter in the next fundamental cycle will be $76^{\prime}, 66^{\prime}, 16^{\prime}$ and $86^{\prime}$ ( in A and C legs the ' 0 ' level is attained by switching on the top switches of the individual inverters and in B-phase the ' 0 ' level is attained by switching the bottom switches ). Now the 'Inverter-2' switches less frequently and 'Inverter-2' switches more.
In case of the outer regions also, the same logic can be applied to translate the switching vectors of the composite three-level inverter to the appropriate combinations of the switching vectors of the individual 2level inverters .

\section{GENERATION OF THE DRIVE SIGNALS FOR THE} DUAL INVERTER

The PWM controller presented in this paper generates the PWM outputs, the sign of the sampled reference voltages and a signal that alternates every fundamental cycle( 'cycle'). The PWM outputs along with the sign information can be decoded to find the corresponding levels in all phases using a simple digital logic . The $\mathrm{Vdc} / 2$ and $-\mathrm{Vdc} / 2$ levels are realised by the appropriate switches in the two inverters. The multiplicity in ' 0 ' level can be resolved using the sign information of the reference voltages and the signal 'cycle' as given in Table 1 ( for A-phase). The signal a-high is ' 1 ' when the Aphase instantaneous reference voltage is positive.

\section{EXPERIMENTAL RESULTS}

The proposed space vector PWM for the dual inverter scheme is implemented for $1 \mathrm{~kW}$ open-end winding induction motor drive. The inverters are run with isolated DC-link voltage of $200 \mathrm{~V}\left(\mathrm{~V}_{\mathrm{dc}} / 2\right)$. The controller is implemented on TMS320F240 DSP platform and the gate signal generation logic is implemented in PAL22v10.The drive is run in the continuous mode under $v / f$ control and is found to make smooth transition from the lower modulation index to the over-modulation region. To observe the waveforms when the reference vector is in different regions the drive is accelerated with different set speeds and the experimental results are presented. Fig.6a shows the phase voltage when the reference vector is moving through the inner region ( modulation index $\mathrm{m}=0.4$ ). The Fig.6b shows the pole voltage of inverter-1 ( $\left.\mathrm{v}_{\mathrm{AlO}}\right)$ and Fig.6c shows the pole voltage of the inverter- $2\left(\mathrm{v}_{\mathrm{A} 2 \mathrm{O}^{\prime}}\right)$. Since these waveforms were separately taken, they do not show their phase relation. Their phase relation is evident in Fig.6d which shows the drive signals generated for these inverters( which are the replica of the pole voltages). It is seen the inverter which switches less frequently for one fundamental cycle, switches more in the next cycle and both inverters are switching equally over a period of two fundamental cycles.Fig.6e shows the rnotor phase current at no load.

Fig.7a shows the phase voltage when the reference vector is moving through the outer region ( modulation index $\mathrm{m}=0.7)$ and it shows all the levels possible in the phase voltage. The Fig. $7 \mathrm{~b}$ shows the pole voltage of Inverter-1 and Fig.7c shows the pole voltage of the Inverter-2. Fig.7d shows the phase current for this modulation index. Fig.8 shows the phase voltage when the drive is running in the over-modulation range where the reference voltage space phasor is made to trace the outer hexagon. It shows that switchings are reduced as the 
switching time period $T_{S}$ in the over-modulation condition is shared by only the middle vectors and the start and end vector durations become zero.

\section{CONCLUSION}

A space vector based PWM strategy for the dualinverter fed open-end winding induction motor, using only the instantaneous sampled reference voltages is presented in this paper. The proposed method does not involve any complex computations or mapping of sectors and hence is simpler for implementation. The switching vectors for the dual inverter are automatically generated without using any look up table. The proposed method ensures equal switchings in both the inverters without using any switching sequence table. The transition from one inverter state to another is achieved by switching only one inverter. An overmodulation strategy is included to control the drive beyond the linear modulation range.

\section{ACKNOWLEDGMENT}

The authors acknowledge Mr.Sanjeev Mohopatra of Texas Instruments, India for providing the DSP platform and development tools.

\section{REFERENCES}

[I] H.Stemmler, P.Guggenbach, "Configurations of high power voltage source inverter drives", EPE.Conference-1993, Brighton, U.K., p.7-12.

[2 JE.G.Shivakumar,K.Gopakumar, V.T.Ranganathan,"Space vector PWM control of dual inverter fed open-end winding induction motor drive",EPE Journal. Vol.12, n". I, Feb 2002,pp. 9- I8

[3] V.T.Somasekhar, K.Gopakumar, E.G Shivakumar, A.Pittet, “A Multilevel Space phasor generation for an open-end winding induction motor drive using a dual inverter scheme with asymmetrical DC link voltages", in EPE Journal, Vol. 12. n 3, Aug, 2002.pp 21-29

[4] V.T. Somasekhar,K.Gopakumar, A.Pittet and V.T.Ranganathan "PWM Inverter switching strategy for a dual two-level inverter fed open end winding induction motor drive with a switched neutral ",IEE ProseedingsElectr.Power Appl. ,vol. 149,No.2,March 2002, pp. 152-160.

[5] Yoshitaka Kawabata, Motoshi Nasu.Takuya Nomoto, Emenike .C..Eijiogu and Takao Kawabata, "High Efficiency and Low Acoustic Noise Drive Using Open-Winding AC Motor and Two Space vector modulated Inverters", IEEE Trans. on Ind.Electronics, vol.49, No.4,Aug 2002 pp. 783.789.

[6]Fei Wang "Sine-triangle versus Space Vector Modulation for ThreeLevel PWM Voltage Source Inverters" IEEE Trans. Ind.Applicat., vol 38,No.2,Mar/Apr 2002,pp.500-506.

[7] Joohn-Sheok Kim and Seung-Ki Sul "A Novel Voltage Modulation technique of the space Vector PWM"Conf.proceedings IPEC'95 pp 742747.

\begin{tabular}{|c|c|c|c|}
\hline $\begin{array}{c}\text { a-high } \\
\text { (from DSP) }\end{array}$ & $\begin{array}{l}\text { Cycle } \\
\text { (from DSP) }\end{array}$ & $\begin{array}{c}\text { Top switch status } \\
\text { of Inverter-1 }\end{array}$ & $\begin{array}{c}\text { Top } \\
\text { switch } \\
\text { status of } \\
\text { Inverter-2 }\end{array}$ \\
\hline 1 & 0 & ON & ON \\
\hline 1 & 1 & OFF & OFF \\
\hline 0 & 0 & OFF & OFF \\
\hline 0 & 1 & ON & ON \\
\hline
\end{tabular}

MULTIPLICITY IN ' 0 ’ LEVEL

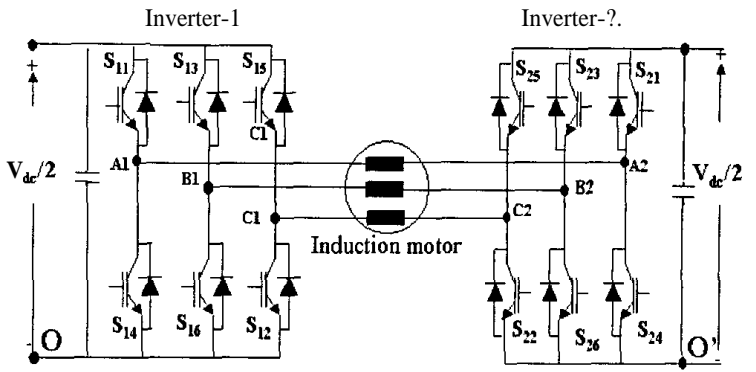

Fig.1 Dual-inverter fed open-end winding induction motor drive

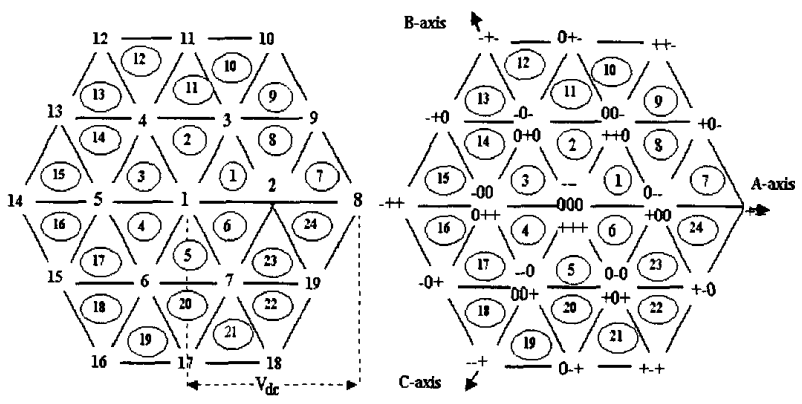

Fig. 2The space vector representation of the dual inverter :locations and the combined switching vectors

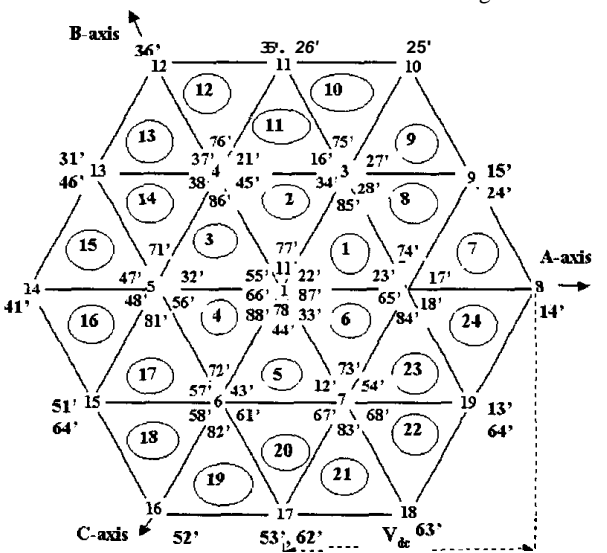

Fig. 3 The space vector diagram of dual inverter with all the switching vector combinations

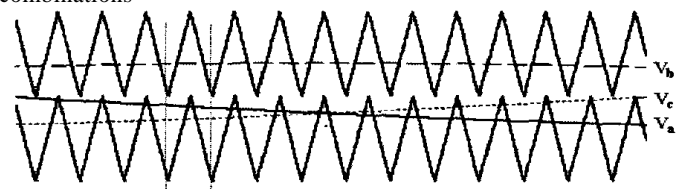

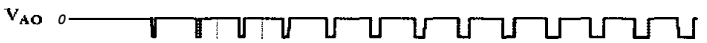
во

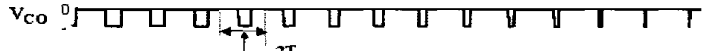

Fig 4a The reference waves, carrier waves and the pole voltages when the space vector is inside the inner hexagon and the middle phase is negative 


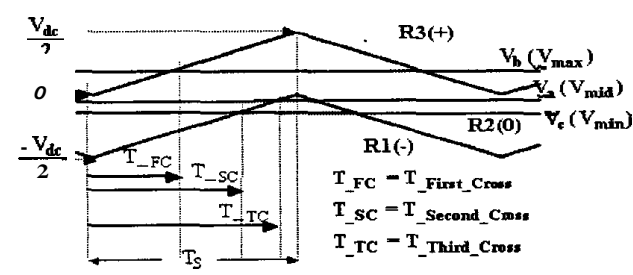

Fig $4 \mathrm{~b}$ The expanded view of the camrer waves and reference signals

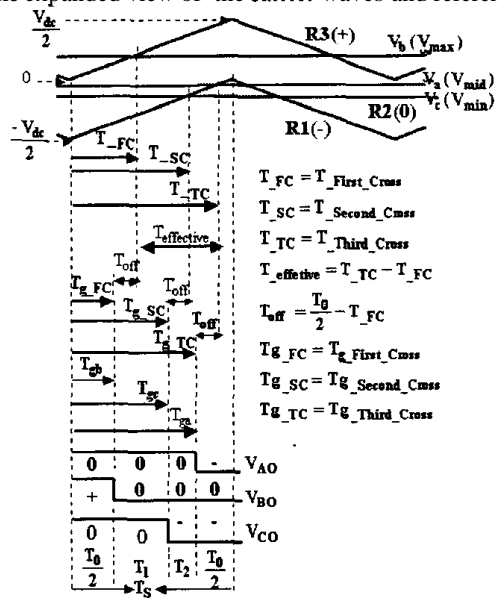

Fig. 5 Principle of the generation of the switching vectors with the

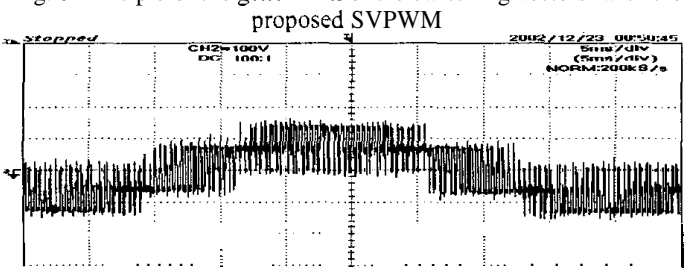

Fig 6a Motor Phase voltage $(\mathrm{m}=0.4)[\mathrm{x}$ axis $1 \mathrm{div}=5 \mathrm{msec}$ y axis $1 \mathrm{div}=$

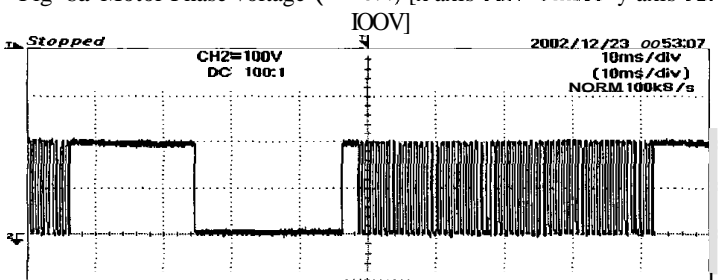

Fig 6b.A-phase Pole voltage of Inverter-I $(\mathrm{m}=\mathrm{O} 4)$ [ $x$ axis 1 div $=10 \mathrm{msec}$ y axis $1 \mathrm{div}=\mathrm{IOOV}]$

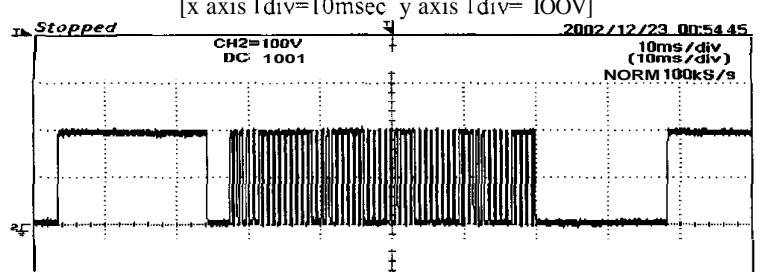

Fig 6c. A- phase Pole voltage of Inverter-2 $(\mathrm{m}=\mathrm{O} 4)$ [ $\mathrm{x}$ axis $1 \mathrm{div}=10 \mathrm{msec}$ : $\mathrm{y}$ axis $1 \mathrm{div}=\mathrm{IOOV}]$

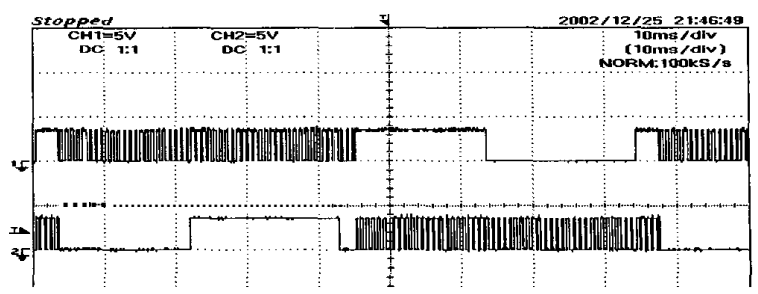

Fig. 6d Dnve signal for top switch of A-leg in Inverter-1(Top ) and Inverter-2 (Bottom $)(\mathrm{m}=04)$. [ $\mathrm{x}$ axis $1 \mathrm{div}=10 \mathrm{msec}$ : $\mathrm{y}$ axis $1 \mathrm{div}=5 \mathrm{~V}]$

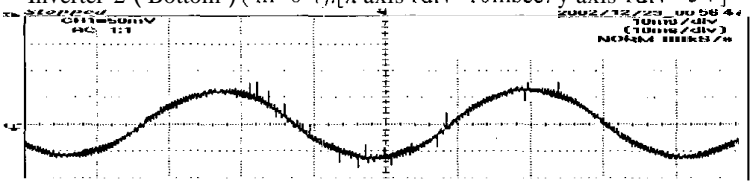

Fig. 6e Motor phase current at no-load $(\mathrm{m}=\mathrm{O} 4)$. [ $\mathrm{x}$ axis $1 \mathrm{div}=10 \mathrm{msec}$ : $y$ axis $1 \mathrm{div}=\mathrm{IA}$ ]

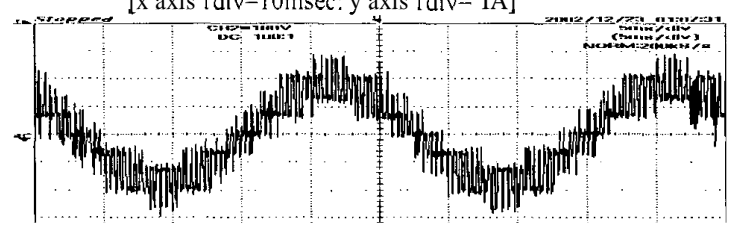

Fig 7a. Motor Phase voltage $(m=0.7)$ [ $\mathrm{x}$ axis $1 \mathrm{div}=5 \mathrm{msec}$ : axis $1 \mathrm{div}=\mathrm{IOOV}]$

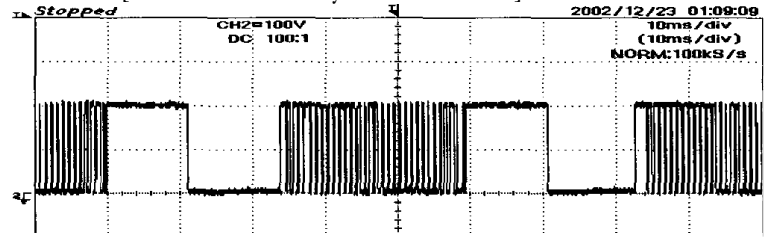

Fig. 7b.A-phase Pole voltage of Inverter-I $(\mathrm{m}=0.7)$.

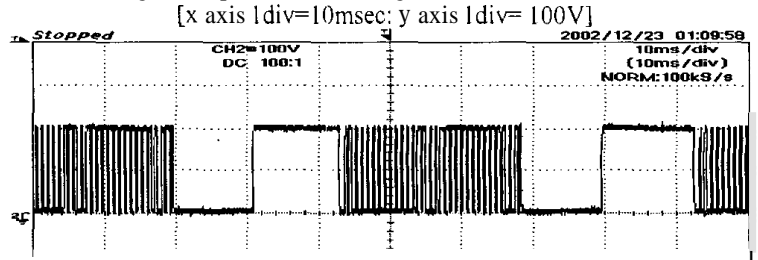

Fig 7c A-phase Pole voltage of Inverter-I $(\mathrm{m}=\mathrm{O} 7)$

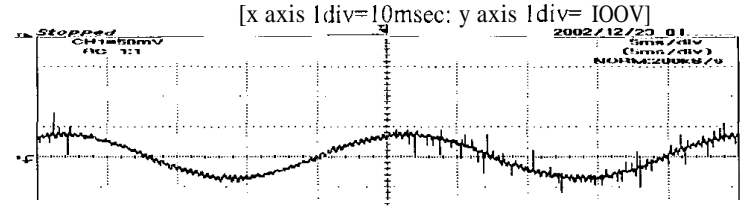

Fig. 7 d. Motor phase current at no-load $(m=0.7)$ [x axis Idiv $=5$ msec: $y$ axis 1 div $=1 \mathrm{~A}]$

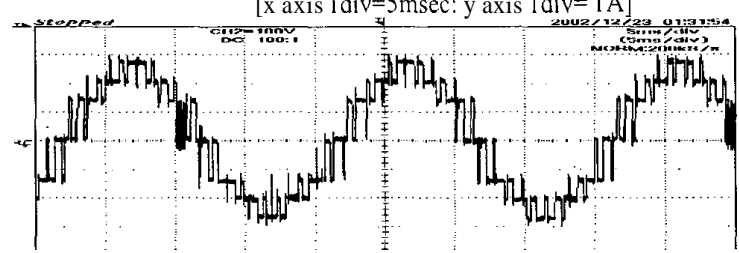

Fig 8 Motor Phase voltage (over modulation) [ $\mathrm{x}$ axis $1 \mathrm{div}=5 \mathrm{msec}$ y axis $1 \mathrm{div}=\mathrm{IOOV}$ ] 